\title{
An Analysis of Solar Burst Type II, III, and IV and Determination of a Drift Rate of a Single Type III Solar Burst
}

\author{
Z. S. Hamidi ${ }^{1, *}$, M. B. Ibrahim ${ }^{1}$, N. N. M. Shariff ${ }^{2}$, C. Monstein ${ }^{3}$ \\ ${ }^{1}$ School of Physics and Material Sciences, Faculty of Sciences, MARA University of Technology, \\ 40450, Shah Alam, Selangor, Malaysia \\ ${ }^{2}$ Academy of Contemporary Islamic Studies (ACIS), MARA University of Technology, \\ 40450, Shah Alam, Selangor, Malaysia \\ ${ }^{3}$ Institute of Astronomy, Wolfgang-Pauli-Strasse 27, Building HIT, \\ Floor J, CH-8093 Zurich, Switzerland \\ *E-mail address: zetysh@salam.uitm.edu.my
}

\begin{abstract}
The main feature of solar radio type II, III and IV burst is outlined. In this event there are three combinations of bursts that related to the solar flare phenomenon on 6th July 2012. This event is one of good example to observe how far the influence of type II burst could impact the formation of type IV burst and III solar bursts. At first stage, it was observed that a sub-type of $\mathrm{H}$ burst form within 2 minutes before type IV solar burst form. The type IV burst is due to the eruption of active region AR 1515 with a fine structure (FS). We used a Blein CALLISTO data in this case. Further analysis also showed that the total energy of the burst are in the range of $4.875 \times 10^{-25} \mathrm{~J}$ to $8.48 \times 10^{-25} \mathrm{~J}$ and plasma frequency is equal to $1.24 \times 10^{4} \mathrm{~Hz}$. Therefore, we could say that in this case, before the solar burst type III occurred, the ejection of CMEs already ejected.
\end{abstract}

Keywords: Sun; solar burst; type II, III,IV; radio region; X-ray region; solar flare; active region

\section{INTRODUCTION}

Type IV burst is an indicator of the formation of a new active region [1-3]. It reveals a wave-particle and wave-wave interactions in magnetic traps in the solar corona [4]. However, the fully developed type IV event is very complex. At meter wavelengths the type IV burst is usually, though not invariably, preceded by a type II (slow-drift) burst. There are two main categories of solar radio burst type IV, which is (i) broadband radio pulsations (BBP) and (ii) zebra patterns (ZP). The fine structures (FS) of solar type IV radio bursts are of principal interest in flare plasma diagnostics in the low corona [5]. We will understand the necessary conditions in the coronal sources. On the other hand, the BBP source starts near the active region and decays away from it [6]. Interestingly, the motion follows the predominant magnetic field direction, the apparent speed is a significant fraction of the speed of light. These BBPs and ZPs in solar type IV radio emission are rather frequently observed, especially a few days before solar flare and Coronal Mass Ejection phenomena [7-9]. 
Meanwhile, solar radio burst type III solar burst is the most dominant with the solar flare phenomenon was first introduced by Wild in 1963 [10] in the frequency range $500-10$ $\mathrm{MHz}$ [11-13]. There are three sub-types of Type III burst that originate in the interplanetary (IP) medium which are (i) isolated Type III bursts from energy system and small-scale energy releases, (ii) a complex Type III bursts during CMEs, and (iii) Type III storms. This stage can be considered as a pre-flare stage that could be a signature of electron acceleration [14]. It is found that $60 \%$ of fast drifts (type III) solar radio bursts are synchronized in time with solar flares [15]. Some evidence showed that type III are generated in a weak-field region comes from the absence or low degree of circular polarization of the bursts [16]. But the most important is that the nonlinear wave-wave interaction which involving interaction of electrostatic electron plasma that called as Langmuir waves active region radio emissions is believed to be a main subject that relevant with a type III burst [17-21]. It is believed that a beam-plasma system is unstable to the generation of Langmuir waves, which are high frequency plasma waves at the local plasma frequency [22,23]. The dynamic structure of the Type III solar burst is well known due to the ejection of plasma oscillations localized disturbance due to excited atoms in the plasma frequency incoherent radiations such as gyro synchrotron and free-free emissions appear in the radio wavelengths play a dominant role at the meter and decimeter wavelengths [24,25]. The common occurrence of Type III bursts early in the rise of impulsive solar flares may indicate that open field lines are an essential part of models for energy release by magnetic fields in such flares [26,27].

Type II solar burst was also discovered roughly more than 60 years ago [28,29]. It can be divided into two main components which is (i) fundamental (F) and (ii) harmonic $(\mathrm{H})$ structure and a slow drift burst [30]. The temperature that implied between these two classes of emission is from $10^{7}-10^{13} \mathrm{~K}[31,32]$. There are two main categories of this burst which is (i) herringbone emission and (ii) backbone emission [33]. The onset time of this type precludes the possibility of the CME driven shock causing it [34]. The motion of the shock through the radial plasma density profile can be observed based on the decreasing of the signal in frequency. One can deduce the propagation speed of the driving shock wave from eruption region. SRBT II were first identified by [35] and also discovered by [36] and classified as a broadband lasting from 20 minutes to a few hours. Thus the CME kinetic energy is the indicator of the life time of the type II bursts [37,38]. Nevertheless, it is important to analyze in radio and x-ray region to understand the distribution of high and low energy [39-42]. The next section will highlight the solar flare and solar bursts in X-ray and radio region.

\section{SOLAR FLARE OBSERVATION}

Solar flare is one of the main event of the Sun that affect the space weather and climate changes [43-45]. The observation of solar radio burst was done by using the Compact Astronomical Low cost, Low frequency Instrument for Spectroscopy and Transportable Observatory (CALLISTO) from BLEIN 7 meter dish telescope at ETH, Zurich in frequency range of 45 until $870 \mathrm{MHz}$. [46,47]. On our site, we also have constructed a log-periodic antenna is a broadband, multi-element, unidirectional, narrow-beam antenna that has impedance and radiation characteristics that are regularly repetitive as a logarithmic function of the excitation frequency [31,32,45,48,49]. This antenna covered from 45-870 MHz [50-53]. The CALLISTO spectrometer is a low-cost radio spectrometer used to monitor metric and decametric radio bursts, and which has been deployed to a number of sites space world to 
allow for 24 hour monitoring of solar radio activity [54,58]. In this case, we focused the range of $150 \mathrm{MHz}$ till $900 \mathrm{MHz}[59,61]$. This region is the best region with minimum interference at Blein, Switzerland site [62,63]. We have selected the data from the $150 \mathrm{MHz}$ till $900 \mathrm{MHz}$ region seems this is the best range with a very minimum of Radio Frequency Interference (RFI) [63,67-69]. In this paper, we have focused the study area of solar flares in an X-ray and radio region to evaluate the distribution of high and low energy [50].

\section{RESULTS AND ANALYSIS}

A class of the M2 solar flare is continuously being observed in X-ray region for 24 hours since 1541 UT and maximum M1 detected on 0140 UT. Based on the calculation, the total energy is high due to high frequency. Then, the plasma frequency also is high which about $1.24 \times 10^{4} \mathrm{~Hz}$. The drift rate also greater as the burst occur in high frequency and in a short time. It should be noted that the solar wind is when a steam of plasma released from the upper atmosphere of the sun and it is consists of mostly electron and proton.

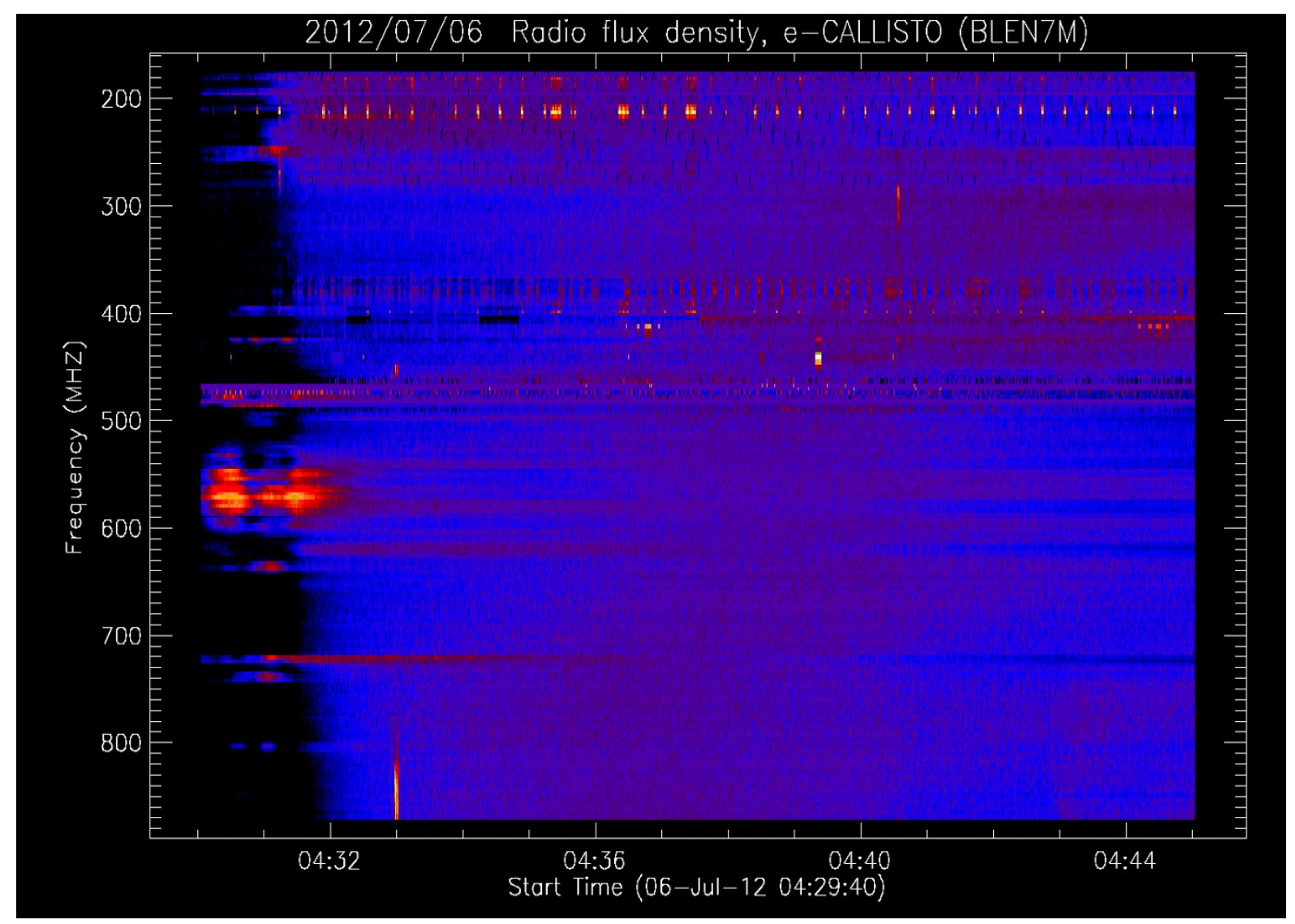

Figure 1. The continuous solar radio burst type IV within 10 minutes (Credited to: E-Callisto network (BLEIN7M)). 


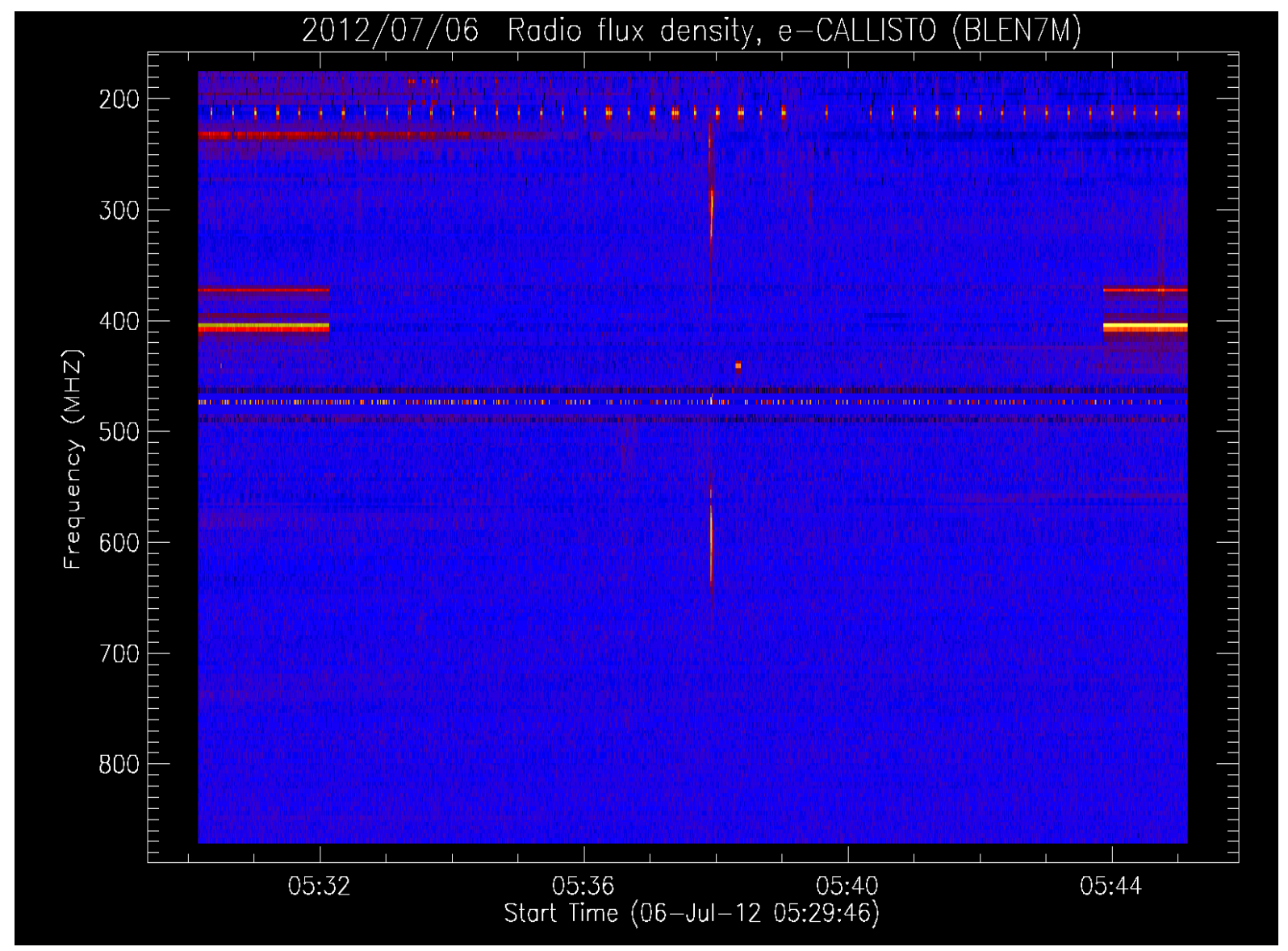

Figure 2. A single solar radio burst type III appears 45 minutes after solar radio burst type IV (Credited to: : E-Callisto network (BLEIN7M)).

Based on calculations, energy for the burst, the total energy of the burst are in the range of $4.875 \times 10^{-25} \mathrm{~J}$ to $8.48 \times 10^{-25} \mathrm{~J}$. The energy released is higher than the first case because of their occurred at high frequency. From the theoretical point of view, the drift velocity also calculated based on the formula as shown below:

$$
\begin{aligned}
& \frac{d f}{d t}=\frac{f \text { high }-f \text { low }}{t \text { high-t low }} \\
& \frac{d f}{d t}=\frac{(800-460) \mathrm{Mhz}}{(1) \text { Second }} \\
& =\frac{130 \mathrm{MHz}}{1 \text { second }} \\
& =340 \mathrm{MHz} / \text { second }
\end{aligned}
$$


We can also possible to find the plasma frequency calculated,

$$
\begin{aligned}
& V p=\underline{\sqrt{e 2 N e}} \\
& 4 \pi \varepsilon_{0} \mathrm{~m}_{\mathrm{e}} \\
& =\sqrt{81 N e \mathrm{~Hz}} \\
& =1.24 \times 10^{4} \mathrm{~Hz}
\end{aligned}
$$

Here, we can conclude that the plasma frequency is directly proportional to solar wind as the solar wind increased, the plasma frequency increased as well.

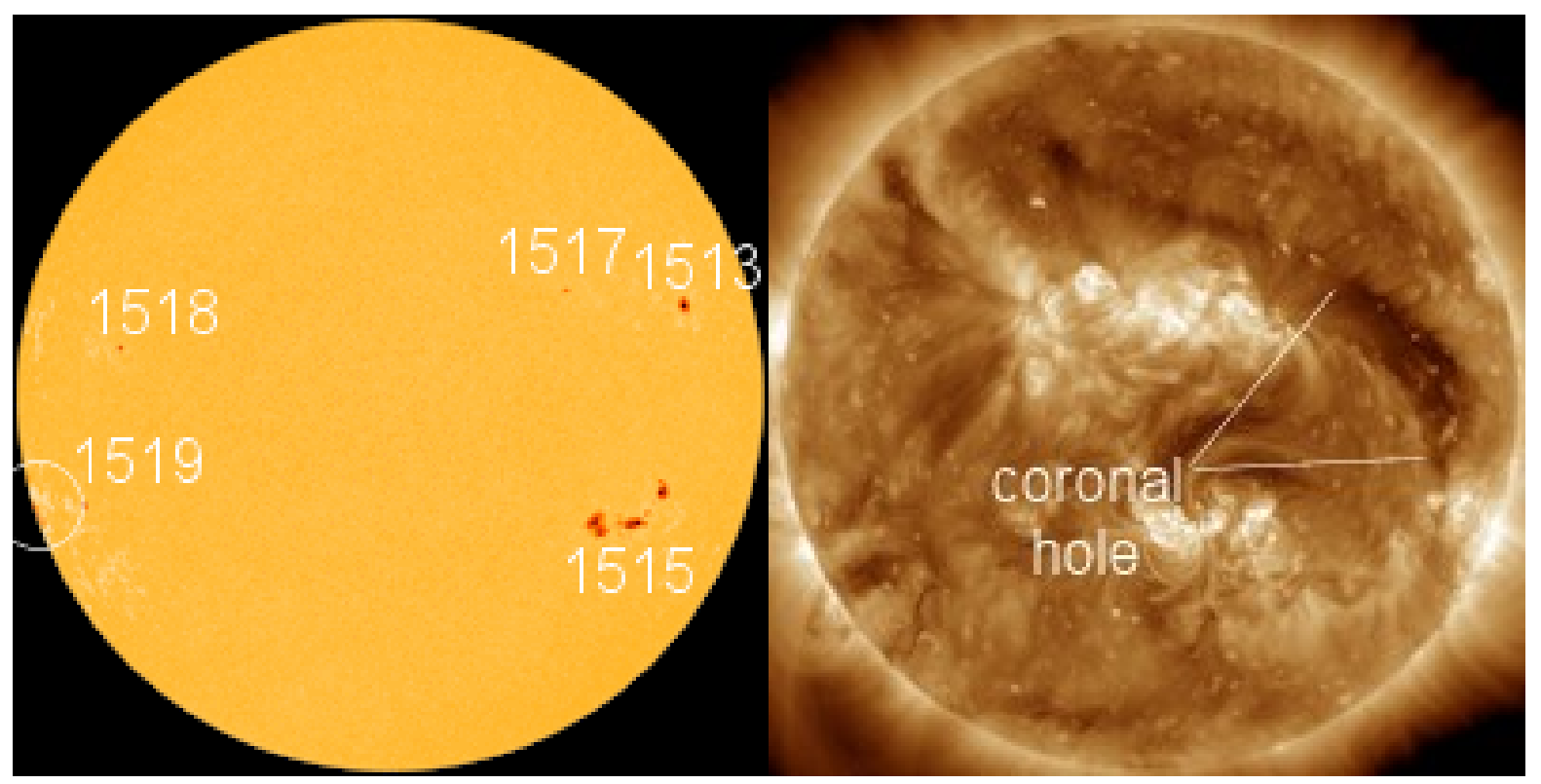

Figure 3. The Active regions during $6^{\text {th }}$ July 2012 and the image of the Sun by X-ray from Space Weather Website (Credited to: NOAA/ SWPC).

It was found that there are five Active Regions on with coronal holes on the Earthfacing side of the Sun. From the Figure 4. The active region AR1515 play the roles to eject the solar flares.

The number of sunspots during the day is up to 122 with the radio flux also high which is $165 \mathrm{SFU}$. The speed of the solar wind also exceeds $480.1 \mathrm{~km} / \mathrm{second}$ with a high density of protons in solar corona which is 1.9 protons $/ \mathrm{cm}^{3}$. 
GOES X-ray Flux (1 minute data)

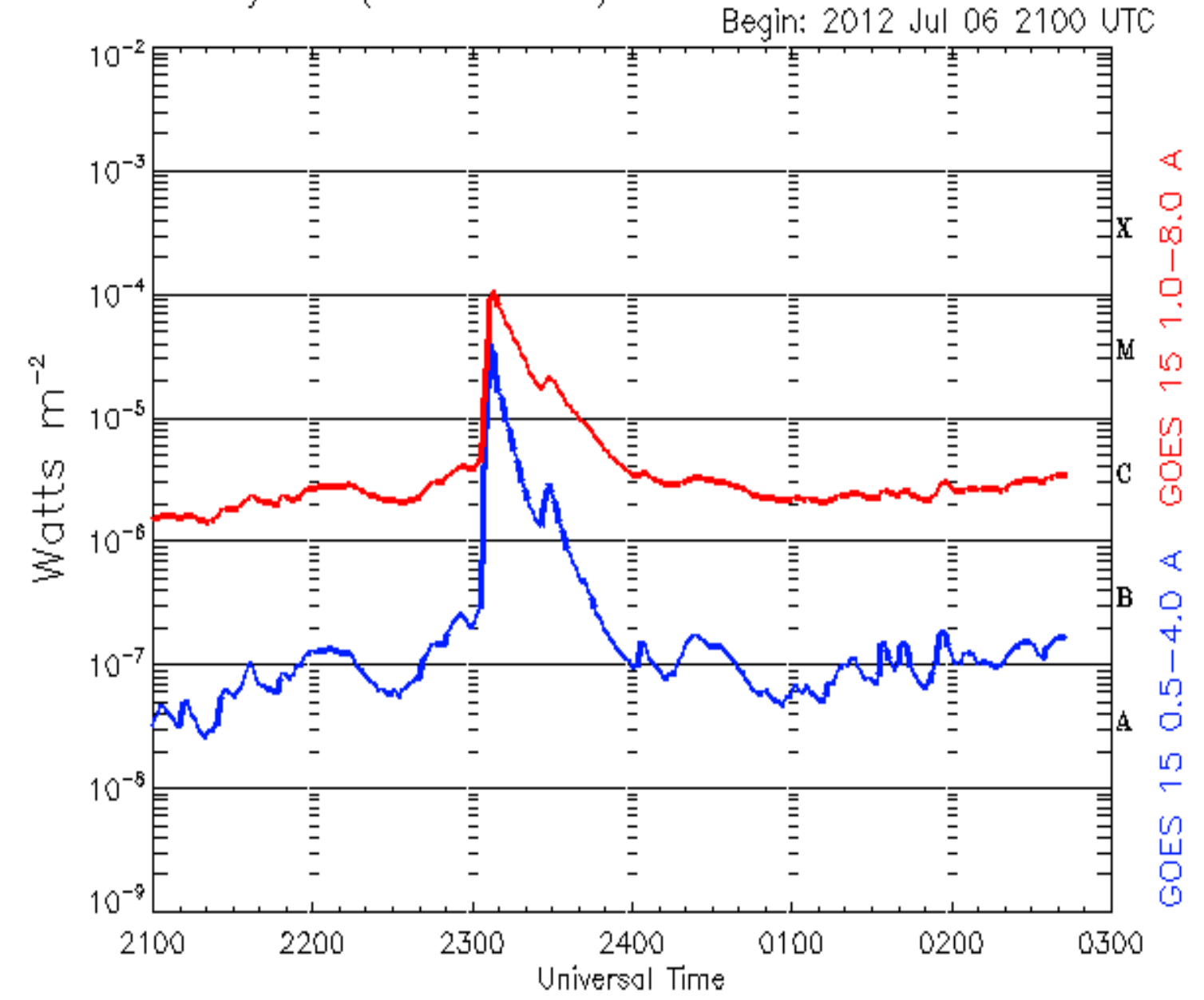

Updated 2012 Jul 70244 UTC

NOAA/SWPC Boulder, CO USA

Figure 4. The variability of solar flare during $6^{\text {th }}$ July 2012 (Credited to NOAA Space Environment Centre).

\section{CONCLUDING REMARKS}

This event is one of good example to observe how far the influence of type II burst could impact the formation of type IV burst and a single type III solar burst. At first stage, it was observed that a sub-type of $\mathrm{H}$ burst form within 2 minutes before type IV solar burst form. It has been observed that before the burst type III occurred, solar radio burst type IV and Type II also occurred.

It is well known as Type II occurred due to the ejection of Coronal Mass Ejections (CMEs). Then after a few hours, type III burst occurred at very high frequency. The solar flare occurred also is classified as an $\mathrm{M}$ - class during the day. Therefore, we could say that in this case, before the solar burst type III occurred, the ejection of CMEs already ejected. 


\section{Acknowledgement}

We are grateful to CALLISTO network, STEREO, LASCO,SDO/AIA, NOAA and SWPC make their data available online. This work was partially supported by the FRGS (600 RMI/FRGS 5/3 2012) UiTM grants. Special thanks to the National Space Agency and the National Space Centre for giving us a site to set up this project and support this project. Solar burst monitoring is a project of cooperation between the Institute of Astronomy, ETH Zurich, and FHNW Windisch, Switzerland, MARA University of Technology and University of Malaya. This paper also used NOAA Space Weather Prediction Centre (SWPC) for the sunspot, radio flux and solar flare data for comparison purpose. The research has made use of the National Space Centre Facility and a part of an initiative of the International Space Weather Initiative (ISWI) program.

\section{Biography}

Dr Zety Sharizat Hamidi is currently a senior lecturer and focused in Solar Astrophysics research specifically in radio astrophysics at the School of Physics and Material Sciences, Faculty of Sciences, MARA University of Technology, 40450, Shah Alam, Selangor, Malaysia. Involve a project under the International Space Weather Initiative (ISWI) since 2010.

M. B. Ibrahim is an undergraduate Physics student at the School of Physics and Material Sciences, Faculty of Sciences, MARA University of Technology, 40450, Shah Alam, Selangor, Malaysia.

Dr Nur Nafhatun Md Shariff is a senior lecturer in Academy of Contemporary Islamic Studies (ACIS), MARA University of Technology, 40450, Shah Alam, Selangor, Malaysia.Her current research is more on sustainability; environmental aspect. She is looking forward for cross-field research, i.e. solar astrophysics, light pollution measurement (mapping) and religious studies.

C. Monstein is a senior Engineer at Institute of Astronomy, Wolfgang-Pauli-Strasse 27, Building HIT, Floor J, CH-8093 Zurich, Switzerland and one of the researchers who initiated the CALLISTO system around the world.

\section{References}

[1] Z. Hamidi, Z. Abidin, Z. Ibrahim, C. Monstein, N. Shariff, M. Sabaghi, The Beginning Impulsive of Solar Burst Type IV Radio Emission Detection Associated with M Type Solar Flare, International Journal of Fundamental Physical Sciences 2 (2012).

[2] Z. Hamidi, N. Shariff, C. Monstein, Disturbances of Solar Eruption From Active Region AR1613, 2014.

[3] Z. Hamidi, N. Shariff, International Letters of Chemistry, Physics and Astronomy 7 (2014) 30-36.

[4] Z. Hamidi, Z. Abidin, Z. Ibrahim, C. Monstein, N. Shariff, Signal Detection Performed by Log Periodic Dipole Antenna (LPDA) in Solar Monitoring, International Journal of Fundamental Physical Sciences (2012).

[5] H. Aurass, Coronal Physics from Radio and Space Observations, in: I.G. Trottet (Ed.), Lecture Notes in Physics, Springer, Berlin, 1997.

[6] A.D. Fokker, Space Science Reviews 2 (1963) 70-90.

[7] C.W. Young, C.L. Spencer, G.E. Moreton, J.A. Roberts, Astrophys. J. 133 (1961).

[8] Ellis, Australian J. Phys. 22 (1969) 167. 
[9] D.J. McLean, a.N.R. Labrum, Solar Radiophysics, Cambridge University Press, Cambridge, 1985.

[10] J.P. Wild, Smerd S.F., and Weiss, A.A., Solar Burst, Ann. Rev. Astron. Astrophysics 1 (1963) 291-366.

[11] Z. Hamidi, N. Shariff, The Propagation of An Impulsive Coronal Mass Ejections (CMEs) due to the High Solar Flares and Moreton Waves, (2014).

[12] Z. Hamidi, U. Ibrahim, U.F. Salwa, Z. Abidin, Z. Ibrahim, N. Shariff, Theoretical Review of Solar Radio Burst III (SRBT III) Associated With of Solar Flare Phenomena, International Journal of Fundamental Physical Sciences 3 (2013).

[13] Z. Hamidi, N. Shariff, C. Monstein, First Light Detection of A Single Solar Radio Burst Type III Due To Solar Flare Event, (2014).

[14] G.A. Dulk, Type III solar radio bursts at long wavelengths, in: R. Stone, E. Weiler, M. Goldstein (Eds.), Geophys. Monogr., 2000.

[15] G. Swarup, P.H. Stone, A. Maxwell, ApJ 131 (1960).

[16] Z. Hamidi, N. Shariff, C. Monstein, Scenario of Solar Radio Burst Type III During Solar Eclipse on 14 th November 2012, (2014).

[17] G.B.a.L. Gelfreikh, B. I., Soviet Astron. 23 (1979).

[18] P. Lantos, Sol. Phys. 22 (1972).

[19] A. Vourlidas, Bastian T. S., Nitta N., Aschwanden M., J., Sol. Phys. 163 (1996).

[20] E.Y. Zlotnik, Soviet Astron. 12 (1968).

[21] V.V. Zheleznyakov, Radio Emission of the Sun and Planets (1970).

[22] Z. Hamidi, N. Shariff, C. Monstein, W.W. Zulkifli, M. Ibrahim, N. Arifin, N. Amran, International Letters of Chemistry, Physics and Astronomy 8 (2014) 13-19.

[23] Z. Hamidi, N. Shariff, C. Monstein, Statistical Study of Nine Months Distribution of Solar Flares, (2014).

[24] Z. Hamidi, Z. Abidin, Z. Ibrahim, C. Monstein, N. Shariff, International Journal of Fundamental Physical Sciencea 2 (2012) 3.

[25] Z. Hamidi, N. Shariff, International Letters of Chemistry, Physics and Astronomy 4 (2014) 29-36.

[26] S.M. White, Asian Journal of Physics 16 (2007) 189-207.

[27] Z.S. Hamidi, N.N.M. Shariff, International Letters of Chemistry, Physics and Astronomy 5 (2014) 32-42.

[28] Z. Hamidi, U.F.S.U. Ibrahim, Z. Abidin, Z. Ibrahim, N. Shariff, International Journal Physical Fundamental Sciences 3 (2013) 20-23.

[29] Z. Hamidi, N. Shariff, C. Monstein, Fundamental and Second Harmonic Bands of Solar Radio Burst Type II Caused by X1. 8-Class Solar Flares, (2014).

[30] Z.S.Hamidi, Z. Abidin, Z. Ibrahim, N. Shariff, C. Monstein, Observations of coronal mass ejections (CMEs) at low frequency radio region on 15th April 2012, in: R.Shukor (Ed.), PERFIK 2012, American Institute of Physics, Malaysia, 2013, pp. 5. 
[31] Z. Hamidi, N. Shariff, International Letters of Chemistry, Physics and Astronomy 7 (2014) 21-29.

[32] Z. Hamidi, N. Shariff, C. Monstein, The Different Between the Temperature of the Solar Burst at the Feed Point of the Log Periodic Dipole Antenna (LPDA) and the CALLISTO Spectrometer, (2014).

[33] Z. Hamidi, N. Shariff, C. Monstein, W.W. Zulkifli, M. Ibrahim, N. Arifin, N. Amran, International Letters of Chemistry, Physics and Astronomy 9 (2014) 8-15.

[34] Gopalswamy, R. N., J. P.,, M.R. Kundu, N. Nitta, J.R. Lemen, R. Herrmann, D. Zarro, T. Kosugi, ApJ 455 (1995).

[35] R. Payne-Scott, D.E. Yabsley, J.G. Bolton, Nature 160 (1947) 256-257.

[36] Boischot, C.R 244 (1957).

[37] N. Gopalswamy, H. Xie, S. Yashiro, I.G. and Usoskin, Coronal mass ejections and ground level enhancements, in: B.e.a. Sripathi Acharya (Ed.), 29th International Cosmic Ray Conference, Pune, India, 2005, pp. 169-172.

[38] Z. Hamidi, N. Shariff, C. Monstein, The Tendencies and Timeline of the Solar Burst Type II Fragmented, (2014).

[39] Z.S. Hamidi, N.N.M. Shariff, M.F. Ali, C. Monstein, W.N.A.W. Zulkifli, M.B. Ibrahim, N.S. Arifin, N.A. Amran, International Letters of Chemistry, Physics and Astronomy 9 (2014) 84-92.

[40] Z.S. Hamidi, N.N.M. Shariff, F.N.Z. Ulum, Z.Z. Abidin, Z.A. Ibrahim, International Journal of Astronomy 5 (2012) 101-106.

[41] Z. Hamidi, International Letters of Chemistry, Physics and Astronomy 16 (2014) 1-85.

[42] Z. Hamidi, C. Monstein, N. Shariff, Radio Observation of Coronal Mass Ejections (CMEs) Due to Flare Related Phenomenon on 7 th March 2012, (2012).

[43] Z. Hamidi, N. Shariff, Enormous Eruption of 2.2 X-class Solar Flares on 10 th June 2014.

[44] Z. Hamidi, N. Shariff, C. Monstein, Understanding Climate Changes in Malaysia Through Space Weather Study, International Letters of Natural Sciences (2014).

[45] Z. Hamidi, N. Shariff, The Mechanism of Signal Processing of Solar Radio Burst Data in E-CALLISTO Network (Malaysia), International Letters of Chemistry, Physics and Astronomy (2014).

[46] Z. Hamidi, N. Shariff, Z. Abidin, Z. Ibrahim, C. Monstein, Malaysian Journal of Science and Technology Studies 9 (2013) 15-22.

[47] Z.S. Hamidi, N. Shariff, Z. Abidin, Z. Ibrahim, C. Monstein, Middle-East Journal of Scientific Research 12 (2012) 6.

[48] Z.S. Hamidi, N.N.M.Shariff, Evaluation of Signal to Noise Ratio (SNR) of Log Periodic Dipole Antenna (LPDA) Business Engineering and Industrial Applications Colloquium 2013, IEEE, Langkawi, Malaysia, 2013, pp. 434-438. 
[49] N. Hashim, Z. Abidin, U. Ibrahim, R. Umar, M. Hassan, Z. Rosli, Z. Hamidi, Z. Ibrahim, Radio Astronomy in Malaysia: Current Status and Outreach Activities, Astronomical Society of the Pacific Conference Series, 2011, pp. 355.

[50] Z.S. Hamidi, Z. Ibrahim, Z. Abidin, M. Maulud, N. Radzin, N. Hamzan, N. Anim, N. Shariff, International Journal of Applied Physics and Mathematics 2 (2011) 3.

[51] Z. Hamidi, N. Shariff, C. Monstein, Evaluation of Spectral Overview and Radio Frequency Interference (RFI) Sources at Four Different Sites in CALLISTO Network at the Narrow Band Solar Monitoring Region, (2014).

[52] Z.S. Hamidi, N.N.M. Shariff, C. Monstein, Z.A. Ibrahim, International Letters of Chemistry, Physics and Astronomy 7 (2014) 37-44.

[53] Z.S. Hamidi, N.N.M. Shariff, Z.A. Ibrahim, Z.Z. Abidin, SOLAR STUDIES IN RADIO EMISSION AND OPTICAL PHOTOMETRY, University of Malaya Publisher, 2013.

[54] Z.S.Hamidi, S. Chumiran, A. Mohamad, N. Shariff, Z. Ibrahim, N. Radzin, N. Hamzan, N. Anim, A. Alias, American Journal of Modern Physics 2 (2013) 4.

[55] Z.S.Hamidi, Z. Abidin, Z. Ibrahim, N. Shariff, C. Monstein, Modification and Performance of Log Periodic Dipole Antenna, International Journal of Engineering Research and Development 3 (2012) 36-39.

[56] Z.S.Hamidi, Z. Abidin, Z. Ibrahim, C. Monstein, N. Shariff, International Journal of Fundamental Physical Sciences 2 (2012) 32-34.

[57] Z.S.Hamidi, N.M.Anim, N. N.S.Hakimi, N.Hamzan, A.Mokhtar, N.Syukri, S.Rohizat, I.Sukma, Z.A. Ibrahim, Z.Z.Abidin, N.N.M.Shariff, C.Monstein, International Journal of Fundamental Physical Sciences 2 (2012) 4.

[58] Z.S.Hamidi, N.N.M. Shariff, International Journal of Science and Mathematics 2 (2014) 3.

[59] Z.S.Hamidi, Z. Abidin, Z. Ibrahim, N. Shariff, Indication of radio frequency interference (RFI) sources for solar burst monitoring in Malaysia, ICPAP 2011, AIP Publisher, Indonesia, 2012, pp. 6.

[60] Z.S. Hamidi, N.N.M. Shariff, C. Monstein, The International Journal of Engineering 1 (2012) 3 .

[61] Z. Hamidi, N. Shariff, C. Monstein, W.W. Zulkifli, M. Ibrahim, N. Arifin, N. Amran, Observation of the Radio Frequency Interference (RFI) at the National Space Centre, Malaysia, International Letters of Natural Sciences (2014).

[62] Z.S. Hamidi, Z.Z. Abidin, Z.A. Ibrahim, N.N.M. Shariff, U.F.S.U. Ibrahim, R. Umar, Preliminary analysis of investigation Radio Frequency Interference (RFI) profile analysis at Universiti Teknologi MARA, IEEE, 2011, pp. 311-313.

[63] R. Umar, Z. Abidin, Z. Ibrahim, N. Gasiprong, K. Asanok, S. Nammahachak, S. Aukkaravittayapun, P. Somboopon, A. Prasit, N. Prasert, Middle East Journal of Scientific Research 14 (2013).

[64] Z.S.Hamidi, N.N.M.Shariff, R.Umar, Malaysia Thailand Journal of Physics 3 (2012) 6.

[65] R. Umar, Z.Z. Abidin, Z.A. Ibrahim, M.S.R. Hassan, Z. Rosli, Z.S. Hamidi, AIP Conference Proceedings 1454 (2012) 39. 
[66] N. Anim, Z. Hamidi, Z. Abidin, C. Monstein, N. Rohizat, Radio frequency interference affecting type III solar burst observations, 2012 NATIONAL PHYSICS CONFERENCE: (PERFIK 2012), American Institute of Physics, 2013, pp. 82-86.

[67] Z. Hamidi, N. Shariff, C. Monstein, International Letters of Chemistry, Physics and Astronomy 10 (2014) 38-45.

[68] Z. S. Hamidi, N. N. M. Shariff, International Letters of Chemistry, Physics and Astronomy 15 (2014) 30-38.

[69] Z. S. Hamidi, N. N. M. Shariff, C. Monstein, International Letters of Chemistry, Physics and Astronomy 18 (2014) 103-112. 